\title{
A PROTOCOL FOR RECORDING BEHAVIORAL ACTIVITY DURING LONGEVITY STUdies of ADUlt Chironomidae
}

\author{
Leonard C. Ferrington Jr. \\ Department of Entomology, 219 Hodson Hall, 1980 Folwell Avenue, University of Minnesota \\ Saint Paul, Minnesota, USA 55108-6125. E-mail: ferri016@umn.edu
}

\begin{abstract}
A protocol for quantifying behaviors of adult Chironomidae during lab-based longevity studies is described and definitions of 12 behaviors are provided. Initial data for field-collected adults from on snow adjacent to three streams during winter, split into batches and incubated at three different temperature treatments, are summarized and show that frequencies of behaviors vary by stream and treatment. Implications of behaviors relative to reproductive fitness of adults is proposed, and changes to the protocol for use in future studies is described.
\end{abstract}

\section{Introduction}

Adults of the winter-emerging chironomid, Diamesa mendotae Mutkowski, have been shown to be long-lived when incubated at low air temperatures (Bouchard et al. 2006a, 2006b, Ferrington et al. 2010), including exposures to extended sub-freezing temperatures (Anderson et al. 2013, Mazack et al. 2015) and capable of walking on snow or resuming flight after landing on snow. It has been proposed that the long duration of the adult portion of the life-cycle provides increased fitness during winter, allowing extended opportunities to mate on snow, and for females to return to the water surface to complete oviposition (Ferrington et al. 2010). However, it is uncertain how meaningful it is to extrapolate lab-based longevity studies to fitness benefits under field conditions and, despite having a longer duration of the adult portion of the life-cycle, it is not possible within the design of previous longevity studies to determine how long the female remains healthy enough to effectively navigate back to the water to oviposit.

Longevity studies of Drosophila melanogaster and Ceratitis capitata, both species that feed as adults, have shown age-specific and lifetime behavior patterns (Carey et al. 2006, Jones and Grotewiel 2011), and the patterns have been quantified using well-defined behavioral categories that are recorded over the adult life span (Connolly and Tully 1998, Carey et al. 2006). Specific behaviors have been shown to be associated with longer life spans (Zhang et al. 2006), functional senescence (Grotewiel et al. 2005), or are effective predictors of time to death (Papadapoulos et al. 2002), which are all essential for understanding the evolution of life cycle dynamics. Studies of predictability and hierarchy of behavioral sequences can inform understanding of how insects interact with the proximate conditions of their environment and provide insight into potential fitness attributes associated with the evolution of specific behaviors (Carey 2003, Berman et al. 2016).

Most species of chironomids are considered to be non-feeding and short-lived as adults. Energy and nutrients for mating and reproduction are accumulated by the larval stages (Tokeshi 1995) and there is an energetic, and corresponding fitness cost, associated with increased longevity and delayed reproduction by adults. Consequently, in many species adults are often able to mate and oviposit within minutes of emerging. Swarming behaviors, as a mechanism for enhancing encounter efficiency and short-range mate recognition among adults, have been described and implications for reproductive success proposed (Neems et al. 1992), however, little is known about the corresponding mechanisms and behaviors of obligate or facultative surface-mating species. It seems plausible to assume that if a longer adult life span in a winteremerging species has increased fitness attributes, specific behaviors would have age-specific or hierarchical relationships that off-set the energetic consequences of delayed reproduction in nonfeeding species.

A well-defined and consistently applied protocol is necessary to record and quantify behavioral patterns. The lab methods used for determining longevity at predetermined, nearly constant, air temperatures consists of daily checks of adults confined individually in one-dram vials to determine when adults die (Ferrington et al. 2010). Routine observations of fly activity in the vials over the duration of earlier experiments have revealed several different behaviors, and recently a protocol has been developed to record behaviors as the flies age. The intent of this publication is to 
define twelve behaviors observed during the longevity studies, and to demonstrate the frequencies of behaviors as a function of incubation temperatures and across three different collection sites. Although I have only developed and applied this protocol in longevity studies of Diamesa mendotae, I anticipate that it can be applied more generally in comparative longevity studies among Chironomidae.

\section{Methods and materials}

Adults of Diamesa mendotae were all scooped from on snow into one-dram vials along with a small amount of snow. When incubated at temperatures above freezing the snow melts and forms a layer of water in the bottom of vials to provide moisture and prevent desiccation. Vials were placed in small coolers partially filled with snow to keep vials from warming on sunny days. Coolers were returned to lab and adults were sorted by sex and briefly observed under dissecting scope to confirm that they were not damaged during collection, then were randomly assigned to differing treatment categories based on predetermined incubation temperatures of $6{ }^{\circ} \mathrm{C}$., $18{ }^{\circ} \mathrm{C}$, and room temperature set at $24{ }^{\circ} \mathrm{C}$. Flies assigned to both the $6{ }^{\circ} \mathrm{C}$. and $18{ }^{\circ} \mathrm{C}$. treatments were incubated in a Sanyo MIR-154 Incubator with temperature fluctuations of $+/-1.5$ degrees, which closely matched the $+/-2{ }^{\circ} \mathrm{C}$. fluctuations in room temperature. The number of specimens per treatment category depended on the number and sex ratios of flies collected in the field and details are provided in Table 1. The field and incubation protocols are consistent with those used in our previous studies of longevity of this species (e.g. Ferrington et al. 2010).

All vials were placed in small cardboard boxes with numbers added to the cap of the vial so that records of behaviors could be traced over time for each fly (Figure 1). Care was taken to not jostle the box and to carefully remove each vial to observe the initial behavior. Initial behaviors were recorded within 15 seconds of removing a vial from the box using a dissecting microscope set at $6 \mathrm{x}$ magnification, at approximately the same time each day. However, as flies aged it was often necessary to tap the vial or increase the observation time up to 30 seconds in order to determine if flies were still alive.

An electronic data sheet in EXCEL format was developed for each fly. After determining the initial behavior of the fly in a vial, an " $X$ " was entered into the corresponding cell in the electronic data sheet. Twelve individual behaviors were incorporated into the data sheet based on the most active or prominent behaviors of flies during the initial

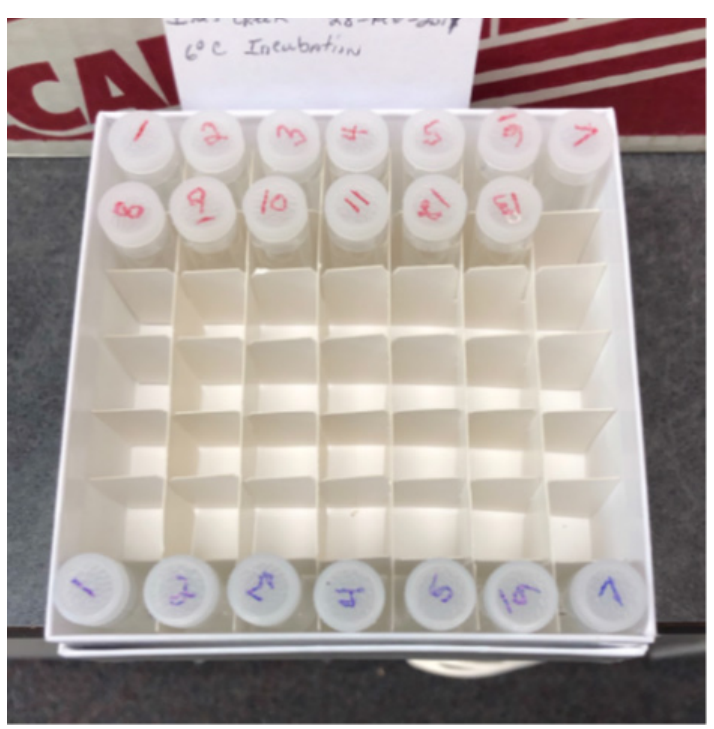

Figure 1. Photograph of cardboard box used to organize numbered vials during longevity studies.

Table 1. Summary of field collections and numbers of Diamesa mendotae used in each longevity treatment temperature. A total of 353 flies were analyzed (219 males and 134 females).

\begin{tabular}{lllll}
\hline Locality & Date DD/MO/YR & $\begin{array}{l}\text { Incubation } \\
\text { Temperature }\end{array}$ & $\begin{array}{l}\text { Number of } \\
\text { Males/Females }\end{array}$ & $\begin{array}{l}\text { Maximum longevities } \\
\text { (days) Males/Females }\end{array}$ \\
\hline Hay Creek & $17 / 02 / 19$ & $24{ }^{\circ} \mathrm{C}$ & $19 / 20$ & $4 / 6$ \\
Hay Creek & $17 / 02 / 19$ & $18{ }^{\circ} \mathrm{C}$ & $18 / 20$ & $12 / 12$ \\
Hay Creek & $17 / 02 / 19$ & $6{ }^{\circ} \mathrm{C}$ & $17 / 19$ & $28 / 30$ \\
Trout Brook & $14 / 02 / 19$ & $24{ }^{\circ} \mathrm{C}$ & $29 / 13$ & $5 / 2$ \\
Trout Brook & $14 / 02 / 19$ & $18{ }^{\circ} \mathrm{C}$ & $29 / 13$ & $10 / 8$ \\
Trout Brook & $14 / 02 / 19$ & $6{ }^{\circ} \mathrm{C}$ & $29 / 13$ & $27 / 28$ \\
Valley Creek & $23 / 02 / 19$ & $24{ }^{\circ} \mathrm{C}$ & $26 / 12$ & $4 / 4$ \\
Valley Creek & $23 / 02 / 19$ & $18{ }^{\circ} \mathrm{C}$ & $26 / 12$ & $7 / 5$ \\
Valley Creek & $23 / 02 / 19$ & $6{ }^{\circ} \mathrm{C}$ & $26 / 12$ & $23 / 19$ \\
\hline
\end{tabular}




\begin{tabular}{|l|l|l|l|l|l|l|l|l|l|l|l|l|}
\hline Date Collected: 17 February 2019 & & & & & & & & & & & & \\
\hline Incubation Temperature: 18 C. & & & & & & & & & & & & \\
\hline Male Number: 12 & & & & & & & & & & & & \\
\hline \multicolumn{1}{|c|}{ CondITION } & 1 & 2 & 3 & 4 & 5 & 6 & 7 & 8 & 9 & 10 & 11 & 12 \\
\hline \hline 1: Perched in cap & & & & & & & & & & & & \\
\hline 2: On side of vial, upper 1/3 & $\mathrm{X}$ & & & & & & & & & & & \\
\hline 3: On side of vial, middle 1/3 & & & & & & & & & & & & \\
\hline 4: On side of vial, lower 1/3 & & $\mathrm{X}$ & & & & & & & & & & \\
\hline 5: Sticking to inside of vial & & & & & & & & & & & & \\
\hline 6: Standing on water, flies when tapped & & & $\mathrm{X}$ & $\mathrm{X}$ & $\mathrm{X}$ & & & & & & & \\
\hline 7: Standing on water, does not fly & & & & & & $\mathrm{X}$ & & & & & & \\
\hline 8: On side, on water, legs moving & & & & & & & & & & & & \\
\hline 9: On water, on back, legs moving & & & & & & & & & & & & \\
\hline 10: Sinking into water, on side & & & & & & & & & & & & \\
\hline 11: Sinking into water, on back & & & & & & & & & & & & \\
\hline 12: Moves only slightly when tapped & & & & & & & & & & & & \\
\hline 13: Dead & & & & & & & $\mathrm{X}$ & & & & & \\
\hline
\end{tabular}

\begin{tabular}{|l|l|l|l|l|l|l|l|l|l|l|l|l|}
\hline Date Collected: 17 February 2019 & & & & & & & & & & & & \\
\hline Incubation Temperature: 18 c. & & & & & & & & & & & & \\
\hline Female Number: 12 & & & & OVI & & & & & & & & \\
\hline \multicolumn{1}{|c|}{ CONDITION } & 1 & 2 & 3 & 4 & 5 & 6 & 7 & 8 & 9 & 10 & 11 & 12 \\
\hline Days post collection & & & & & & & & & & & & \\
\hline 1: Perched in cap & & & & & & & & & & & & \\
\hline 2: On side of vial, upper 1/3 & & & & & & & & & & & & \\
\hline 3: On side of vial, middle 1/3 & & & & & & & & & & & & \\
\hline 4: On side of vial, lower 1/3 & & & & & & & & & & & & \\
\hline 5: Sticking to inside of vial & & & & & & & & & & & & \\
\hline 6: Standing on water, flies when tapped & $X$ & $X$ & $X$ & $X$ & $X$ & & & & & & & \\
\hline 7: Standing on water, does not fly & & & & & & $X$ & $X$ & & & & & \\
\hline 8: On side, on water, legs moving & & & & & & & & & & & & \\
\hline 9: On water, on back, legs moving & & & & & & & & & & & & \\
\hline 10: Sinking into water, on side & & & & & & & & & & & & \\
\hline 11: Sinking into water, on back & & & & & & & & $X$ & & & & \\
\hline 12: Moves only slightly when tapped & & & & & & & & & & & & \\
\hline 13: Dead & & & & & & & & & $X$ & & & \\
\hline
\end{tabular}

Figure 2. Example of data sheet and daily records of behavior for a male and female collected from on snow, 17 February 2019, adjacent to Hay Creek, Goodhue County, MN. The female oviposited in the vial on Day 4, post collection.

assessments. Each behavior was assigned a number. Oviposition date was also entered into the data sheet, as was observations of mites on flies and nematodes observed in the water. See Figure 2 as an example of behaviors recorded for a male and a female that oviposited while incubated at $18{ }^{\circ} \mathrm{C}$.

Flies were preserved with $95 \%$ ethanol and locality labels with fly number were placed individually in vials unless the female oviposited. Females that oviposited were transferred to another vial before preservative and labels were added so that eggs could continue to be checked for embryogenesis or larval hatch. Males were checked under higher magnification after preservation to confirm species identity. We currently cannot reliably determine females to species, but assume they are all Diamesa mendotae. All preserved flies have been stored in -80 degree $\mathrm{C}$. freezer for subsequent evaluation.

\section{Results}

\section{Definitions of behaviors}

1) Perched in cap - Adults displaying this behavior tend to remain at rest in the cap when checked, but seem to be the most active when disturbed, often flying for several seconds or more before landing on the inside of the vial or within the cap. Flies landing on the side of the vial generally walk quickly up the inside of the vial and resume their position within the cap. Not all flies exhibit this behavior, and adults obtained from field collections vary substantially in the percent of individuals that perch within the cap.

2) On side of vial, upper $1 / 3$ - This behavior is defined relative to the upper-most part of the body of the fly. In most cases the flies rest with the head up, which serves as the point for determining posi- 
tion on the inside of the vial. When disturbed, they fly or walk quickly up or down the inside of the vial, but rarely land or stand on the water.

3) On side of vial, middle $1 / 3$ - As with behavior 2 , this behavior is defined by the upper-most part of the body, usually the head. When disturbed flies walk or fly within the vial, usually landing on the side, but occasionally standing briefly on the water, then walking back up the inside of the vial.

4) On side of vial, lower $1 / 3$ - This behavior is also measured by the upper-most body part. In contrast to behaviors 2 and 3, flies sometimes orient horizontally or with head up, but often have one or more legs in contact with the water surface. When disturbed they fly but quickly land, or rapidly flutter wings while walking on the inner surface of the vial, or gliding in circles on the water before again resting on the side of the vial. Some adults walk on the inside of the vial and resume resting in the middle or upper $1 / 3$ of the vial.

5) Sticking to inside of vial - Adults exhibiting this condition are generally females that have begun to extrude eggs (but not into the water) or males that appear to have a drop of fluid extruded from near the bases of the gonocoxites (presumably spermataphore). This behavior was coded as 5 because adults that become stuck to the side of the vial are often in the middle or lower $1 / 3$ of the vial (not commonly at the water surface) and often vigorously fan their wings and/or move their legs, sometimes for several days. However, few actually detach from the vial and resume other behaviors before dying. In some instances, adults attempt grooming behaviors with the forelegs and spread fluids to the wings or legs which then can become stuck to the vial.

6) Standing on water, flies when tapped - In contrast to behaviors 1-3, flies exhibiting this behavior commonly rest on the water, but readily fly when the vial is tapped on the stage of the dissecting microscope. After flying briefly, flies commonly return to the water surface or land on the side, generally in the middle or lower $1 / 3$. If not disturbed again, flies remain relatively motionless, or engage in grooming behavior, especially if touching the inside of the vial. If disturbed again by tapping, the flies typically resume flying.

7) Standing on water, does not fly - In contrast to behavior 6 , flies exhibiting this behavior do not fly when the vial is tapped for up to 15 seconds. This behavior, however, has several different outcomes that were observed in the longevity experiments, and it seems useful and informative to sub-divide the definition of this behavior in future experiments. Although the behaviors are likely to be part of a general decline in vigor, by providing definitions, it will be possible to score individuals in subsequent experiments according to the three new definitions provided here. Behavior 7 (a) is defined as individuals that do not fly when disturbed, but fan their wings rapidly and glide in circles or bounce along the water surface before coming to rest, either on the water surface or in the lower $1 / 3$ of the inner surface of the vial. After coming to rest, individuals often engage in grooming behaviors. Behavior 7 (b) consists of short, gentle bursts of fluttering the wings when tapped, but little or no gliding, and rapidly return to standing on the water or in association with the inside of the vial. In some cases, the wings may not be fully folded over the abdomen after fluttering, but are held at an acute angle to the abdomen, or one wing may be fully folded but the other remains at a sharply acute (or less sharply acute) angle to the abdomen. Behavior 7 (c) consists of the adult not fanning or fluttering the wings but walking or remaining motionless on the water. As with Behavior 7 (b), both wings can be fully folded over the abdomen, or one or both wings can remain at an angle to the abdomen.

8) On side, on water, legs moving - Individuals exhibiting this behavior appear to have lost equilibrium and cannot remain standing on the water. Often the adult can still gently flutter the wings and move their legs rapidly while on their side, but no coordinated flying or standing occurs. Some individuals partially or fully upright themselves but are uncoordinated and slip back onto their sides. Wings are usually at an acute angle to the abdomen, not fully folded at rest over the abdomen.

9) On water, on back, legs moving - In contrast to behavior 8 , individuals on their back typically do not flutter their wings or temporarily upright themselves. Wings are often at or near a 90 degree angle to the abdomen, and their upper surfaces are usually fully in contact with the water surface. In this position, legs may be moving rapidly or not, and are usually not contacting the surface of the water.

10) Sinking into water, on side - The ability of adults to remain on the water surface in behaviors 8 or 9 is likely to be a function of waxes secreted onto the epicuticle. Volatilization of waxes and decomposition by microbes can degrade the waxes and reduce the hydrophobic nature to the exoskeleton. It is possible that decreased wax production associated with aging reduces the replenishment of waxes, resulting in adults loosing hydrophobicity 
and sinking into the water during later stages of incubation. Individuals sinking into the water while on their sides generally do not flutter wings, and leg movement is greatly reduced as water pulls up onto the cuticle.

11) Sinking into water, on back - Individuals exhibiting this condition generally are ones that transitioned to it from behavior 9. Typically water will pull up onto the sides of the thorax and/or abdomen, and in the case of males the plume setae can become entrained in the water film or fully sink into the water.

12) Moves only slightly when tapped - Adults exhibiting this behavior may have transitioned from behaviors 8-11 and may be on their side on the surface of the water, or sinking into the water to varying degrees, but not actively moving unless the vial is tapped on the stage of the dissecting microscope, and generally stop moving when tapping is discontinued. Adults transitioning to this behavior from behaviors 1-7 often look very healthy and may be on the water surface near the meniscus with the side of the vial, or even partially sticking to the vial, and also only move in response to tapping. No attempts to fly or walk occur. In some cases the only visible indications that the adult is still alive are subtle movements of the palps and/ or twitching of legs, leg segments, antennae, gonocoxite, gonostylus or cercus

13) Dead - In some instances it is easy to discern that the individual is dead. Adults transitioning to death from behaviors 1-7 often have legs or wings at unusual angles to the body, presumably as rigor mortis results in muscle tissue contracting and distorting the distal portions at odd angles to the more proximal parts of the joint or segment. In addition, there can be very striking and conspicuous asymmetries in the orientation of legs, wings, antennae and/or palps. These adults also are often floating on the water surface and readily are displaced when tapping the vial. Adults transitioning from 8-11, however, often do not exhibit legs or wings at unusual angles or high degrees of asymmetry, but often show some degree of microbial growth, usually fungal, that can be detected at higher magnification. When an adult has been presumed to be dead, the observation time is often increased before recording the individual as dead.

\section{Adult Longevities}

Maximum longevities of males and females as a function of collection stream and incubation temperatures are shown in Table 1. Longevities of males incubated at $24{ }^{\circ} \mathrm{C}$. ranged from 4-5 days versus 2-6 days for females. At $18{ }^{\circ} \mathrm{C}$. male longevities ranged from 7-12 days compared to 5-12 days for females. Longevities of both males and females were longest at $6{ }^{\circ} \mathrm{C}$. incubation, ranging from 23-28 and 19-30 days, respectively.

\section{Scoring of Behaviors}

Daily assessments of individual behaviors were recorded for 353 flies (Table 2). Quantification of behaviors as a function of collection locality and incubation temperatures is shown in Table 2. A total of 2,744 behaviors were recorded, including 228 for incubations at $24{ }^{\circ} \mathrm{C}$., 666 at $18{ }^{\circ} \mathrm{C}$. and 1,731 at $6^{\circ} \mathrm{C}$. Figures 3-5 show histograms of frequencies of behaviors exhibited by batches of flies collected at different localities and held at the three different incubation temperatures.

\section{Discussion}

The behaviors defined in this study are based on earlier routine observations of the types of activities of field collected adults exhibit when observed in vials during longevity experiments under lab conditions at predetermined intervals after col-

Table 2. Summary of numbers of behavioral observations of Diamesa mendotae obtained for each longevity treatment temperature.

\begin{tabular}{llll}
\hline Locality & $\begin{array}{l}\text { Incubation } \\
\text { Temperature }\end{array}$ & $\begin{array}{l}\text { Number of observations } \\
\text { (including "Dead") }\end{array}$ & $\begin{array}{l}\text { Number of observations } \\
\text { (excluding "Dead") }\end{array}$ \\
\hline Hay Creek & $24{ }^{\circ} \mathrm{C}$ & 159 & 120 \\
Hay Creek & $18{ }^{\circ} \mathrm{C}$ & 287 & 249 \\
Hay Creek & $6{ }^{\circ} \mathrm{C}$ & 675 & 644 \\
Trout Brook & $24{ }^{\circ} \mathrm{C}$ & 106 & 64 \\
Trout Brook & $18{ }^{\circ} \mathrm{C}$ & 229 & 187 \\
Trout Brook & $6{ }^{\circ} \mathrm{C}$ & 629 & 587 \\
Valley Creek & $24{ }^{\circ} \mathrm{C}$ & 82 & 44 \\
Valley Creek & $18{ }^{\circ} \mathrm{C}$ & 150 & 112 \\
Valley Creek & $6{ }^{\circ} \mathrm{C}$ & 427 & 389 \\
\hline
\end{tabular}




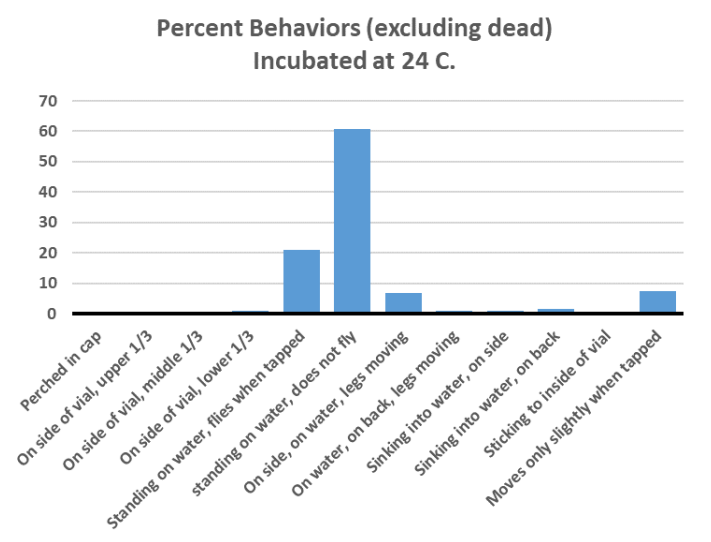

Percent of Behaviors (excluding dead) Incubated at $18 \mathrm{C}$.

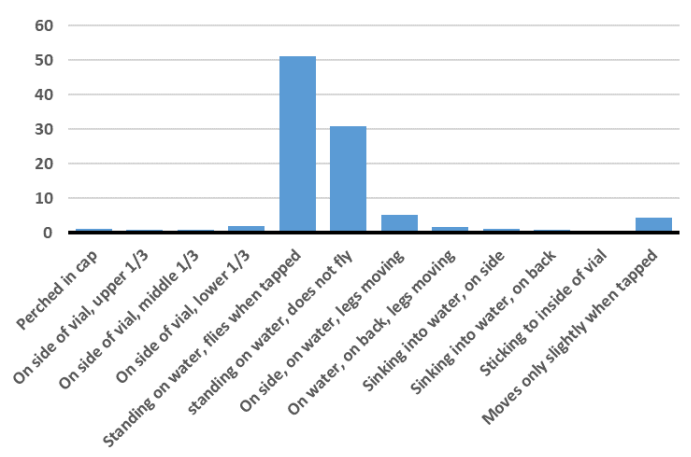

Percent of Behaviors (excluding dead) Incubated at 6 C.

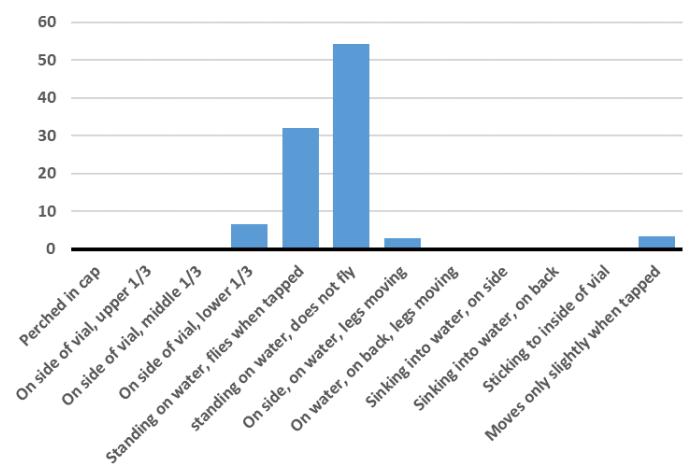

Figure 3. Percent of behaviors recorded by adult flies collected from Hay Creek during longevity experiments with adults incubated at different temperatures.

lection. Differing behaviors were recorded in lab notes, but until recently no attempts were made to standardize definitions for the behaviors, and no prior attempts were made to score the behaviors in a systematic manner. The results presented in this paper thus represent the first application of the protocol. As defined here, all behaviors can readily be assessed within 15 seconds among recently collected batches of adults. However, as longevity studies progress and adults age, it is often necessary to increase the time observing the specimens in order to determine if they are alive, but relatively non-responsive, or dead.
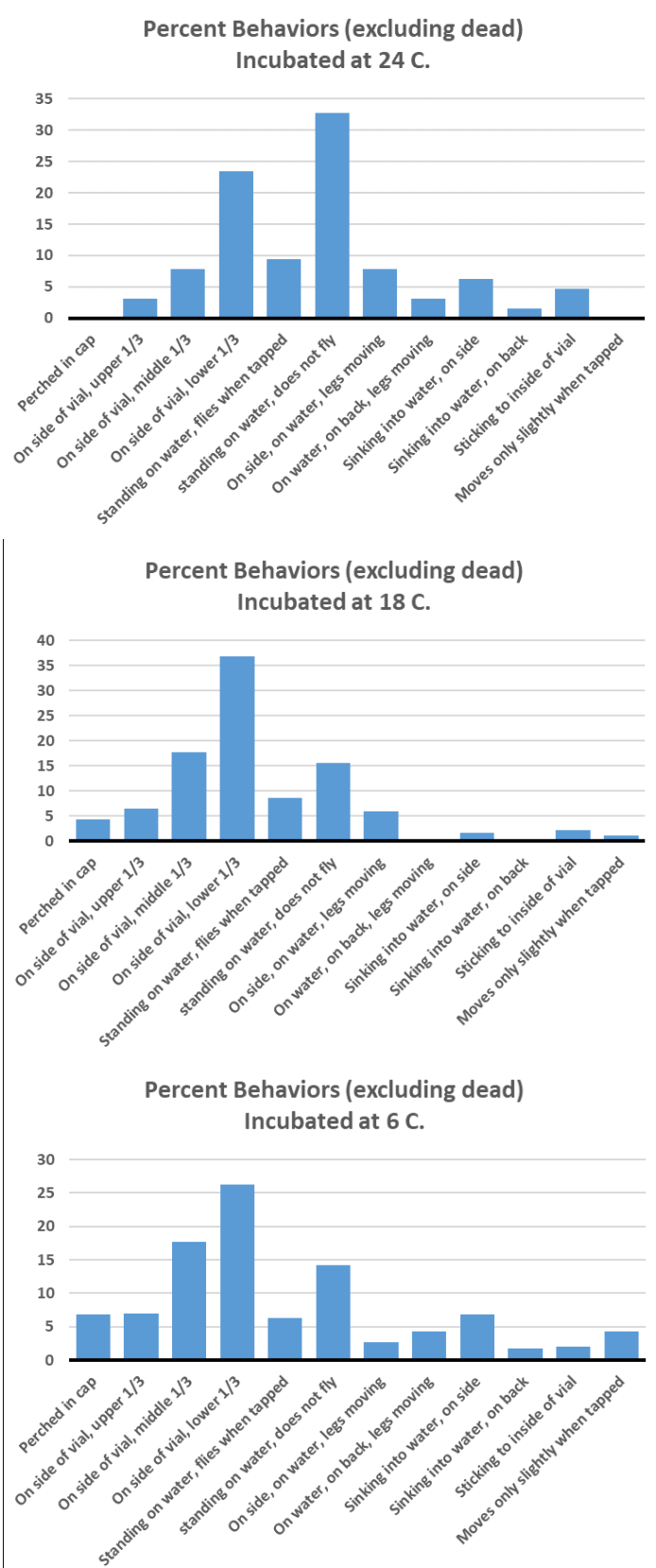

Figure 4. Percent of behaviors recorded by adult flies collected from Trout Brook during longevity experiments with adults incubated at different temperatures.

Behavior 7, Standing on water, does not fly, requires further comment and will be subdivided in future studies. Although the behaviors are likely to be part of a general decline in vigor, I anticipate that it will be possible to unambiguously score individuals in subsequent experiments according to the three new definitions provided here. Behavior 7 (a) is distinctive in that individuals that do not fly when disturbed fan their wings rapidly and glide in circles or bounce along the water surface before coming to rest. This behavior can persist for several or many seconds, often continuing for the entire 15 second observation interval. 


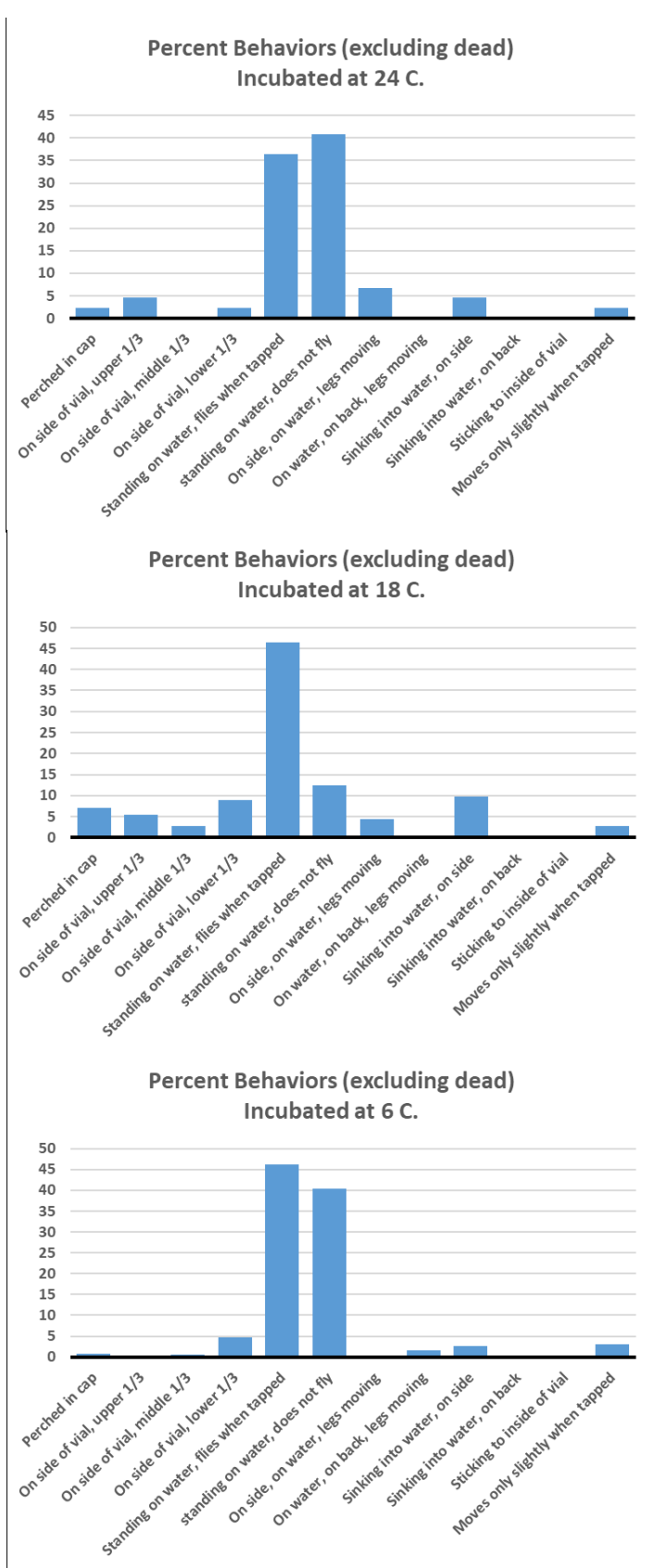

Figure 5. Percent of behaviors recorded by adult flies collected from Valley Creek during longevity experiments with adults incubated at different temperatures.

Behavior 7 (b), which is defined as consisting of short, gentle bursts of fluttering the wings when tapped, differs qualitatively from 7 (a), but in most cases it is combined with little or no gliding activity, and adults rapidly return to standing on the water or in association with the inside of the vial, often within 3-4 seconds after tapping the vial. As noted earlier, in some cases the wings may not be fully folded over the abdomen, but are held at an acute angle to the abdomen, or one wing may be fully folded but the other remains at an angle to the abdomen.
Behavior 7 (c) consists of the adult not fanning or fluttering the wings but walking or remaining motionless on the water. To assess this condition it is necessary to observe the adult for the entire 15 second interval, and repeatedly tap the vial on the stage of the microscope. Similar to behavior 7 (b), both wings can be fully folded over the abdomen, or one or both wings can remain at an angle to the abdomen and adults rarely attempt to maintain contact with the inner surface of the vial. Adults often are very unstable, shaking or quivering while attempting to remain upright on the water.

Division of behavior 7 into three distinct behaviors will add to the sensitivity to future study of transitions in behavior from ones with high activity to lower activity, and will lead to better interpretation of fitness states, transitions to higher morbidity, and quantification of age-related impairment in locomotor and other behaviors as shown for Drosophila by Jones and Grotewiel. (2011). The revised protocol will have 14 behavioral categories.

As mentioned in the introduction, it is uncertain how meaningful it is to extrapolate lab-based longevity studies to fitness benefits under field conditions. Despite having a longer duration of the adult portion of the life-cycle, if the female does not remain healthy enough to effectively navigate back to the water to oviposit, her reproductive potential is lost. Using the new definitions to record behaviors, it is likely that females exhibiting behaviors $7 \mathrm{~b}$ through 12 are not capable of returning to the stream. By contrast, females on a snow bank, but in close proximity to the stream, may still have potential to fan their wings sufficiently to glide across snow (behavior 7a) and navigate to the open water to oviposit.

Although not quantified in earlier longevity studies, previous routine observations of collections from differing streams and under different field temperature conditions have indicated there are small to substantial differences in the frequencies of behaviors, especially behaviors 1-6. As shown here (Figures 3-5), there are differences in the frequencies of behaviors 1-7 for the three collections, but the differences are most conspicuous when comparing the frequencies of behaviors 1 , 2 and 3 for adults from Hay Creek versus Trout Brook. Based on the limited number of field collections that have been quantified using the protocol, it is not yet possible to offer an interpretation for the population-to-population variability of lab behaviors. However, Carey (2011) has shown population differences in longevities and behavior patterns among wild-caught populations of six 
medfly global biotypes. Although speculative, it is possible that population differences in cold-adaptedness of Diamesa mendotae could influence the lab expressions of adult behaviors.

\section{Acknowledgements}

Many members of the Chironomidae Research Group have contributed to the long term success of our studies of the cold-adapted life cycle of Diamesa mendotae. In addition, most colleagues and guests visiting our lab during winter over the past twenty-five years have been introduced to a "winter collecting experience" of picking adults from on snow adjacent to trout streams in Minnesota or Kansas. The list of persons contributing to this research through field-collecting of adults on snow is far too long to include all their names. However, I would like to extend my gratitude to all for your help, and hope the winter experience was pleasurable. Facilities and incidental support for this research was provided by the Department of Entomology at the University of Minnesota. Grant support from the Legislative-Citizen Commission on Minnesota Resources (LCCMR Project \# 03i) and Minnesota Agricultural Experiment Station Project (MAES 17-031) to the author.

\section{References}

Anderson, A.M., Kranzfelder, P., Bouchard, R.W., Jr. and Ferrington, L.C., Jr. 2013. Survivorship and longevity of Diamesa mendotae Muttkowski (Diptera: Chironomidae) under snow. - Journal of Entomological and Acarological Research 45(6): 22-26. DOI: http://dx.doi. org/10.4081/jear.2013.e6

Berman, G.J., Bialek, W. and Shaevitz, J.W. 2016. Predictability and hierarchy in Drosophila behavior. - Proceedings National Academy of Sciences 113(42): 11942-11948. DOI: https:// doi.org/10.1073/pnas.1607601113

Bouchard, R.W., Jr, Carrillo, M.A., and Ferrington, L.C., Jr. 2006a. Lower lethal temperature for adult male Diamesa mendotae Muttkowski (Diptera: Chironomidae), a winter-emerging aquatic insect - Aquatic Insects 28(1): 57-66.

Bouchard, R.W., Jr, Carrillo, M.A., Kells, S.A. and Ferrington, L.C., Jr. 2006b. Freeze tolerance in larvae of the winter-active Diamesa mendotae Muttkowski (Diptera: Chironomidae): A contrast to adult strategy for survival at low temperatures. - Hydrobiologia 568: 403-406.

Bouchard, R.W., Jr. and Ferrington, L.C., Jr. 2009. Winter growth, development, and emergence of Diamesa mendotae (Diptera: Chironomi- dae) in Minnesota streams. - Environmental Entomology 38(1): 250-259.

Carey, J.R. 2003. Longevity: the Biology and Demography of Lifespan. Princeton University Press. $304 \mathrm{pp}$.

Carey, J.R. 2010. Biodemography of the Mediterranean fruit fly: Aging, longevity and adaptation in the wild. - Experimental Gerontology 46: 404-411.

Carey, J.R., Papadopoulos, N., Kouloussis, N., Katsoyannos, B., Müller, H-G., Wang, J-L. and Tseng, Y-K. 2006. Age-specific and lifetime behavior patterns in Drosophila melanogaster and the Mediterranean fruit fly, Ceratitis capitata. - Experimental Gerontology 41: 93-97. DOI: https://doi.org/10.1016/j. exger.2005.09.014

Connolly, J.B., Tully, T. 1998. Behaviour, learning and memory. In: Roberts, D.B., (Ed.) Drosophila, A Practical Approach. IRL Press at Oxford University Press, Oxford, pp. 265-317.

Ferrington, L.C., Jr, Bouchard, R.W., Jr, and Karns, B. 2010. Longevities of Diamesa Mendotae Muttkowski, a hibernal emerging species of Chironomidae (Diptera). In: Ferrington (Ed.) Proceedings of the XV International Symposium on Chironomidae, pp. 22-29.

Grotewiel, M.S., Martin, I., Bhandari, P., CookWiens, E. 2005. Functional senescence in Drosophila melanogaster. - Ageing Research Reviews 4: 372-397

Jones, M.A. and M. Grotewiel. 2011. Drosophila as a model for age-related impairment in locomotor and other behaviors. - Experimental Gerontology 46: 320-325.

Mazack, J., Kranzfelder, P., Anderson, A.M., Bouchard, R.W., Jr., Perry, J., Vondracek, B. and Ferrington, L.C., Jr. 2015. Survivorship and longevity of adult Diamesa mendotae Muttkowski, 1915 (Diptera: Chironomidae) at controlled, subfreezing temperatures. - Aquatic Insects: International Journal of Freshwater Entomology 36(1): 1-8. DOI: https://doi.org/1 $\underline{0.1080 / 01650424.2014 .990040}$

Neems, R.M., Lazarus, J. and McLachlan, A.J. 1992. Swarming behavior in male chironomid midges: a cost-benefit analysis. - Behavioral Ecology 3: 285-290.

Papadopoulos, N.T., Carey, J.R., Katsoyannos, B.I., Kouloussis, N.A., Müller, H-G. and Liu X. 2002. Supine behaviour predicts time-to- 
death in male Mediterranean fruit flies. - Proceedings of the Royal Society of London: Biological Sciences 269: 1633-1637.

Tokeshi, M. 1995. Life cycles and population dynamics. In: Armitage, P.D., Cranston, P.S. and Pinder, L.C.V. (Eds.) The Chironomidae. Springer, Dordrecht.
Zhang, Y., Müller, H-G., Carey, J.R. and Papadopoulos, N.T. 2006. Behavioral trajectories as predictors in event history analysis: Male calling behavior forecasts medfly longevity. Mech Ageing Development 127(8): 680-686.

Article submitted 3. August 2019, accepted by Barbara Hayford 21. October 2019, published 10. November 2019. 